\title{
Efektivitas Pelayanan Perangkat Desa oleh Kepemimpinan Kepala Desa (Datuk Penghulu)
}

\section{Effectiveness of Service Village Devices of the Leadership's the Village Head (Datuk Penghulu)}

\author{
Muhammad Hardiansyah'), Muhammad Arif Nasution') \\ \& Armansyah Matondang3)
}

\author{
1) Program Studi Ilmu Pemerintahan, Fakultas Ilmu Sosial dan Ilmu Politik \\ Universitas Medan Area, Indonesia \\ 2) Departemen Ilmu Politik, Fakultas Ilmu Sosial dan Ilmu Politik \\ Universitas Sumatera Utara, Indonesia \\ 3) Program Studi Ilmu Komunikasi, Fakultas Ilmu Sosial dan Ilmu Politik \\ Universitas Medan Area, Indonesia
}

Diterima: Mei 2019; Disetujui: Mei 2019; Diterbitkan: Juni 2019.

\begin{abstract}
Abstrak
Penelitian ini bertujuan untuk mengetahui Efektivitas Pelayanan Perangkat Desa oleh Kepemimpinan Kepala Desa (Datuk Penghulu) pada Masyarakat Kampung Kesehatan Kabupaten Aceh Tamiang Tahun 2017. Penelitian ini menggunakan metode deksriptif kualitatif, teknik pengumpulan data adalah wawancara, observasi dan dokumentasi lokasi penelitian dilakukan di Kampung Kesehatan kecamatan Karang Baru Kabupaten Aceh Tamiang. Hasil penelitian menunjukkan bahwa pemimpin dapat mempengaruhi moral, kepuasan kerja, keamanan, kualitas kehidupan kerja dan terutama tingkat prestasi suatu organisasi. Kemampuan dan keterampilan dalam pengarahan adalah faktor penting efektivitas suatu organisasi. Faktor penting efektivitas suatu organisasi yaitu: loyalitas, Komunikasi Pengambilan keputusan, Tanggungjawab dan Ketaatan pemimpin terhadap peraturan. Dari penelitian ini, dapat disimpulkan bahwa Kepemimpinan Kepala Desa (Datuk Penghulu) Terhadap Efektivitas Pelayanan Perangkat Desa Pada Masyarakat Kampung Kesehatan Kabupaten Aceh Tamiang Tahun 2017 sudah baik.
\end{abstract}

Kata Kunci: Kepemimpinan, Efektivitas dan Pelayanan.

\begin{abstract}
This study aims to determine the extent of the Leadership of the Village Head (Datuk Penghulu) on the Effectiveness of Village Service Services in the Community of Aceh Tamiang District Health Village in 2017. Leaders can influence morale, job satisfaction, security, work quality and especially the level of achievement of an organization. The ability and skills in direction are important factors for the effectiveness of an organization. By looking at several aspects to determine the effect of Leadership and Measurement of Service Effectiveness in the Health Village of Karang Baru Subdistrict, Aceh Tamiang Regency, namely: loyalty, Decision Making Communication, Responsibility and Obedience of leaders to regulations. in this study using a qualitative descriptive method, the location of the study was conducted in the Health Village of Karang Baru sub-district, Aceh Tamiang Regency. Data collection techniques are interviews, observation and documentation, it can be concluded that the Leadership of the Village Head (Datuk Penghulu) Against the Effectiveness of Service of Village Devices in the Community of Aceh Tamiang District Health Village in 2017 has been good.

Keywords: Leadership, Effectiveness and Service
\end{abstract}

How to Cite: Hardiansyah, M. Nasution, M.A. \& Matondang, A. (2019). Efektivitas Pelayanan Perangkat Desa OLEH Kepemimpinan Kepala Desa (Datuk Penghulu) Tahun 2017. PERSPEKTIF, 8 (1): 1-5. 


\section{PENDAHULUAN}

Tugas pokok pemerintahan desa adalah menjalankan sebagian kewenangan kecamatan serta melaksanakan tugas-tugas lainnya berdasar kepada peraturan yang berlaku. Dalam kapasitasnya sebagai sebuah organisasi pemerintah di bawah Kecamatan, Tujuan penyelenggaraan pemerintahan desa adalah terlaksananya berbagai fungsi kelurahan sesuai dengan kewenangannya yang diberikan oleh kecamatan secara efektif dan efisien, termasuk di dalamnya adalah fungsi pelayanan administrasi aparat kepada masyarakat.

Efektivitas merupakan unsur pokok aktivitas organisasi dalam mencapai tujuan atau sasaran yang telah ditentukan sebelumnya. Bila dilihat dari aspek segi keberhasilan pencapaian tujuan, maka efektivitas adalah memfokuskan pada tingkat pencapaian terhadap tujuan organisasi. Selanjutnya ditinjau dari aspek ketepatan waktu, maka efektivitas adalah tercapainya berbagai sasaran yang telah ditentukan tepat pada waktunya dengan menggunakan sumbersumber tertentu yang telah dialokasikan untuk melakukan berbagai kegiatan.

Untuk mencapai efektivitas pelayanan aparat pada masyarakat yang diinginkan kepala desa Kampung Kesehatan harus menjalankan fungsi dan tugasnya dengan cara memotivasi para pegawainya dan juga selalu berkomunikasi, agar para pegawainya menyadari bahwa mereka memang dibutuhkan dan tidak dibeda-bedakan, sehingga mereka mengerjakan pekerjaan mereka dengan sebaik-baiknya, demi kepuasan masyarakat. Kepala desa juga dibutuhkan untuk mengontrol kegiatan para pegawainya apakah berjalan dengan tujuan yang diinginan atau tidak. Kepala desa dan pegawainya harus saling kerja sama dalam usaha pencapaian tersebut. Masing-masing dari mereka haruslah menyadari tugas dan tanggung jawabnya (Arianto, 2016).

Pemerintah Desa Kampung Kesehatan Kecamatan Karang Baru Kabupaten Aceh Tamiang, yang bekerja dalam pelayanan masyarakat sudah seharusnya memberikan pelayanan yang terbaik kepada masyarakat. Untuk mendapatkan pelayanan yang demikian, pemerintah Desa Kampung Kesehatan Kecamatan Karang Baru Kabupaten Aceh Tamiang harus efektif mungkin dalam menjalankan pekerjaannya. Namun sayang pada prakteknya, sering kali ditemukan pegawai yang tidak bekerja efektif sebagaimana mestinya. Misalnya saja para pegawai sering kali datang terlambat masuk kerja dari jam kerja yang telah ditentukan, bahkan meninggalkan kantor sebelum jam kerja berakhir (pendapat masyarakat). Disinilah tuntutan kepemimpinan seorang kepala desa dalam mengelola para pegawainya agar lebih efektif dalam melaksanakan tugas dan tanggungjawabnya demi menciptakan aparatur pemerintah yang baik dan sehat demi kepuasan masyarakat.

Perangkat desa sebagai bagian dari pegawai negeri dituntut untuk dapat menjadi motor penggerak pembangunan karena aparat kelurahan bersentuhan langsung dengan masyarakat sehingga akan lebih memahami keadaan dan kondisi masyarakat. Dari penjelasan tersebut dapat dikatakan bahwa kesempurnaan birokrasi tergantung dari kesempurnaan aparatur Negara sehingga kualitas birokrasi kita tercermin dari kualitas aparatur Negara.

Menurut Bourjol dan Bodrad (dalam Kaloh, 2002) secara historis, asal usul kata Kepala kelurahanberasal dari bahasa Junani dan Latin Konu seperti koinotes (komunist) dan Demos (ssrakyat atau distrik) yaitu suatu organisasi yang di kendalikan oleh wakilwakil rakyat terpilih dalam suatu wilayah. (Kusmanto, 2015).

Kepemimpinan seorang Kepala Desa di setiap desa mesti mampu menjadi contoh atau teladan yang baik bagi masyarakatnya. Bila di desa mampu melahirkan pemimpin yang bagus dalam melangsungkan pembangunan, maka desa itu akan berubah ke arah yang lebih baik. (Oktavia \& Prayetno, 2018). Memutar terus roda perjalanan bangsa ini dalam rangka me-reform Indonesia yang memerlukan kualitas prima dari gebrakan ide dan semangat dari seorang peimimpin yang energik bagi sebuah kepemimpinan (Suharyanto, 2016).

Pelayanan publik itu sendiri adalah kegiatan atau rangkaian kegiatan dalam rangka pemenuhan kebutuhan pelayanan sesuai dengan peraturan perundang-undangan bagi setiap warga negara dan penduduk atas barang, jasa, dan pelayanan administrasi yang disediakan oleh penyelenggara pelayanan publik. (UU No. 25 / 2009). Efektivitas pelayanan akan meningkat seiring dengan peningkatan mutu pelayanan. Semakin tinggi 
mutu pelayanan bagi masyarakat, maka semakin tinggi pula kepercayaan masyarakat kepada pemerintahan. Dengan demikian akan semakin tinggi pula peran serta masyarakat dalam kegiatan pelayanan.

Maka dari itu peneliti merasa tertarik untuk melakukan penelitian terhadap Kepemimpinan Kepala Desa (Datuk Penghulu) Terhadap Efektivitas Pelayanan Perangkat Desa Pada Masyarakat Kampung Kesehatan Kabupaten Aceh Tamiang Tahun 2017.

Berdarasarkan latar belakang masalah yang diuraikan diatas, maka permasalahan dalam penelitian ini adalah untuk mengetahui bagaimana Kepemimpinan Kepala Desa (Datuk Penghulu) Terhadap Efektivitas Pelayanan Perangkat Desa Pada Masyarakat Kampung Kesehatan Kabupaten Aceh Tamiang Tahun 2017.

\section{METODE PENELITIAN}

Penelitian yang berjudul "Kepemimpinan Kepala Desa (Datuk Penghulu) Terhadap Efektivitas Pelayanan Perangkat Desa Pada Masyarakat Kampung Kesehatan Kabupaten Aceh Tamiang Tahun 2017 ini menggunakan metode Penelitian Kualitatif menurut Sugiyono (2014) metode penelitian kualitatif adalah metode yang digunakan untuk meneliti obyek yang alamiah dimana peneliti sebagai instrument kunci, tehnik pengumpulan data secara triangulasi,analisis databersifat induktif dan hasil penelitian kualitatif lebih menekankan makna.

Dalam metode penelitian kualitatif penulis ikut berpartisipasi langsung ke lapangan. Peneliti melihat, mengamati dan mengumpulkan data melalui wawancara mendalam, observarsi serta dokumentasi berdasarkan fakta di lapangan, melalui hasil tersebut peneliti dapat menuliskan laporan secara detail sehingga menghasilkan pemahaman secara spesifik.

Sutrisno Hadi dalam Sugiyono (2013) observasi merupakan suatu proses yang kompleks, suatu proses yang tersusun dari berbagai proses biologis dan psikhologis. Dua di atara yang terpenting adalah proses-proses pengamatan dan ingatan.

Menurut Esterberg dalam Sugiyono (2013) Wawancara merupakan pertemuan dua orang untuk bertukar informasi dan ide melalui Tanya jawab, sehingga dapat dikontruksikan makna dalam suatu topik tertentu.

Menurut Sugiyono (2013) dokumen merupakan catatan peristiwa yang sudah berlalu. Dokumen bisa berbentuk tulisan, gambar, atau karya-karya monumental dari seorang. Studi dokumen merupakan pelengkap dari penggunaan metode observasi dan wawancara dalam penelitian kualitatif.

Dalam teknik pengumpulan data, triangulasi diartikan sebagai teknik pengumpulan data yang bersifat menggabungkan data dan sumber data yang telah ada.

Analisis data dalam penelitian kualitatif, dilakukan pada saat pengumpulan data berlangsung, dan setelah selesai pengumpulan data dalam periode tertentu. Miles dan Huberman (1984), mengemukakan aktivitas dalam analisis data kualitatif dilakukan secara interaktif dan berlangsung secara terus menerus sampai tuntas, sehingga datanya jenuh. Aktivitas dalam analisis data meliputi: data reduction (reduksi data), data display (penyajian data), dan conclusion drawing (verification dan penarikan kesimpulan). (Sugiyono, 2007).

Moleong (2005) memaparkan tujuan uji (credibility) kredibilitas data yaitu untuk menilai kebenaran dari temuan penelitian kualitatif. Kredibilitas ditunjukkan ketika partisipan mengungkapkan bahwa transkrip penelitian memang benar-benar sebagai pengalaman dirinya sendiri. Dalam hal ini peneliti akan memberikan data yang telah ditranskripkan untuk dibaca ulang oleh partisipan. Kredibilitas menunjukkan kepercayaan terhadap data hasil penelitian kualitatif.

Menurut Moleong (2009) untuk menetapkan keabsahan data (trustworthiness) data diperlukan teknik pemeriksaan. Pelaksanaan teknik pemeriksaan didasarkan atas sejumlah criteria tertentu. Ada empat criteria yang digunakan, yaitu derajat kepercayaan (credibility), keteralihan (transferability), kebergantungan (dependability), dan kepastian (confirmability). Untuk menjaga keabsahan data, maka yang dipergunakan adalah teknik pengamatan lapangan dan teknik triangulasi data. 


\section{HASIL DAN PEMBAHASAN}

Kepala desa dituntut harus mempunyai jiwa kepemimpinan yang baik agar tugas-tugas pemerintah yang menjadi kewajibannya dapat terselesaikan dengan baik, yang mana penulis menggunakan teori dari Susanto \& Kardi, (2003) yang memiliki beberapa Aspek Pengukuran Efektifitas Pelayanan

Berdasarkan hasil wawancara kepda informan Kunci, Utama dan Tambahan Bahwa Evaluasi Kenerja pegawai yang dilakukan telah dilakukan sesusai dengan standart operasional prosedur yang mana Penulis melakukan penelitian menggunakan teori dari Susanto \& Koesnadi, (2003) yang memiliki beberapa Aspek Pengukuran Efektifitas Pelayanan, yaitu sebagai berikut:

\section{Loyalitas}

Dari pernyataan yang diberikan oleh Informan Kunci, Utama dan Tambahan dapat disimpulkan bahwa pungukuran Loyalitas yang dikemukakan Susanto \& Kardi, menjamin baik tidaknya tingkat Kepemimpinan, bahkan di Bagian Kepala Desa (Datuk Penghulu) ini hanya satu yang menjadi pengukur Loyalitas yaitu Efektivitas,dimana setiap pegawai sudah teruji dan memiliki kompetensi yang baik sehingga kecil kemungkinan Loyalitas Kepemimpinan di Kantor Kepala Desa Kampung Kesehatan Kecamatan Karang Baru Kabupaten Aceh Tamiang tidak tercapai.

\section{Komunikasi}

Dari hasil yang sudah dijelaskan oleh Informan Kunci, Utama dan Tambahan yang bekerjasama dengan bagian ini dapat disimpul bahwa Komunikasi yang diberikan Kepala Desa Terhadap Masyarakat dan Perangkat Desa Lainnya sangat baik dan masyarakat yang menerimanya juga merasa puas akan layanan yang diberikan oleh Kepala Desa Kampung Kesehatan Kecamatan Karang Baru Kabupaten Aceh Tamiang sehingga semakin banyak yang ingin bekerjasama untuk memajukan ekonomi mereka dan itu sesuai dengan tujuan dari Kepala Desa itu sendiri.

\section{Pengambilan Keputusan}

Dengan melihat hasil wawancara atas Informan Kunci,Utama dan Tambahan dapat disimpulkan kembali bahwa responsivitas yang diberikan oleh Kepala Desa Kampung
Kesehatan Kecamatan Karang Baru Kabupaten Aceh Tamiang sudah sangat baik mulai dari Survey lapangan,Pengumpulan Aspirasi Masyarakat yang langsung didengar dilokasi serta tim penerima keluh kesah yang di berikan oleh mitra terhadap fenomena yang sedang terajadi di masyarakatnya ini,akan tetapi sayangnya Pengambilan Keputusan yang diberikan tidak di balas dengan baik oleh beberapa Masyarakat yang Kontra,akan tetapi semua berjalan dengan baik dan lancar.

\section{Ketaatan Pemimpin Terhadap Peraturan dan Tanggung Jawab}

Hampir sama dengan Pengambilan Keputusan dimana Ketaatan Pemimpin Terhadap Peraturan dan Tanggung Jawab ini lebih mengacu kepada prinsip- prinsip Adminitrasi yang mana suatu prosen kegiatan admnistrasi yang dilakukan Kepala Desa apakah sudah sesuai dengan Prinsip-prinsip administrasi dan kebijakan dari birokrasi itu sendiri,dan yang terjadi di lingkungan Kantor Kepala Desa Kampung Kesehatan Kecamatan Karang Baru Kabupaten Aceh Tamiang semuanya mengikuti prosedur yang telah ditetapkan oleh Bupati yang mana Bupati merupakan kepala dari seluruh Desa di Kabupaten Aceh Tamiang.

\section{SIMPULAN}

Berdasarkan hasil penelitian dan analisa data sebelumnya,secara umum Kepemimpinan Kepala Desa (Datuk Penghulu) Terhadap Efektivitas Pelayanan Perangkat Desa Pada Masyarakat Kampung Kesehatan Kabupaten Aceh Tamiang Tahun 2017 sudah sangat baik dan lancar dilihat dari hasil yang menggunakan teori dari Susanto \& Kardi, (2003) yang memiliki beberapa Aspek Pengukuran Efektifitas Pelayanan. Untuk mengetahui Kepemimpinan Kepala Desa (Datuk Penghulu) Terhadap Efektivitas Pelayanan Perangkat Desa Pada Masyarakat Kampung Kesehatan Kabupaten Aceh Tamiang Tahun 2017. Terdapat lima (4) yang memiliki beberapa Aspek Pengukuran Efektifitas Pelayanan, diantaranya: 1. Loyalitas, 2. Komunikasi, 3. Pengambilan Keputusan, 4. Ketaatan Pemimpin Tehadap Peraturan dan Tanggung Jawab Dimana keempat indikator tersebut semuanya berjalan dengan baik dan sesuai dengan yang disepakati bersama,dengan kata 
Kepemimpinan Kepala Desa Kampung Kesehatan Kabupaten Aceh Tamiang sudah sangat baik.

\section{DAFTAR PUSTAKA}

Kardi, K. (2003) Aspek Pengukuran Efektifitas Pelayanan. PT. Rajagrafindo Persada: Jakarta

Arianto, B. Warjio, Usman T. (2016), Kepemimpinan Lurah dalam Meningkatkan Motivasi Kerja Perangkat Kelurahan, Jurnal Administrasi Publik, 6 (2): 107-122.

Kaloh, J. (2002). Mencari Bentuk Otonomi Daerah. Jakarta: Rineka Cipta.

Kusmanto, H., (2015). Persepsi Masyarakat Terhadap Upaya Kepala Kelurahan Sebagai Salah Satu Unsur Pelaksana Pemerintahan Kota Medan, Jurnal Ilmu Pemerintahan dan Sosial Politik, 3 (1): 49-57.

Miles, B.M. \& Huberman, M. (1992). Analisis Data Kualitatif Buku Sumber Tentang Metode- metode Baru. Jakarta: UIP Desa. Jakarta: Erlangga.

Moleong, L.J. (2008). Metodologi Penelitian Kualitatif. Bandung: PT. Remaja Rosdakarya.

Oktavia. M. \& Prayetno (2018). Menguji Kepemimpinan Kepala Desa dalam Pembangunan Infrastruktur Desa Rianiate Kecamatan Pangururan Kabupaten Samosir. Journal of Education, Humaniora and Social Sciences (JEHSS). 1 (2): 81-92.

Rivai, V. (2005). Manajemen Sumber Daya Manusia Untuk Perusahaan, Dari Teori Ke Praktek. PT. Rajagrafindo Persada: Jakarta.

Sugiyono. (2013). Metode Penelitian Pendidikan Pendekatan Kuantitatif, Kualitatif, dan R\&D. Bandung: Alfabeta.

Suharyanto, A., Armansyah M., Taufik W.H., (2016), Aktualisasi dan Filosofi Konsep Kepemimpinan Tradisional Bagi Generasi Muda di Bale Marojahan Medan, Jurnal Pendidikan Ilmu-Ilmu Sosial, 8 (2) (2016): 182-189. 